\title{
Methylphenidate-mediated motor control network enhancement in patients with traumatic brain injury
}

Charlie L. Dorer ${ }^{\mathrm{a}}$, Anne E. Manktelowa; Judith Allanson ${ }^{\mathrm{b}}$; Barbara J. Sahakian; John D. Pickard ${ }^{d}$; Andrew Bateman ${ }^{\mathrm{e}}$, David K. Menon ${ }^{\mathrm{a}}$, Emmanuel A. Stamatakis ${ }^{\mathrm{a}}$

Author institutional affiliations:

a) Division of Anaesthesia, University of Cambridge, School of Clinical Medicine, Addenbrooke's Hospital, Cambridge, UK.

b) Cambridge University Hospitals NHS Foundation, Cambridge, UK

c) Department of Psychiatry, University of Cambridge, UK.

d) Academic Neurosurgery Unit, University of Cambridge, UK.

e) Oliver Zangwill Centre, Ely, UK.

Corresponding author: Dr Emmanuel A. Stamatakis, Division of Anaesthesia, University of Cambridge School of Clinical Medicine, Box 93, Addenbrooke's Hospital, Hills Road, Cambridge, CB2 2QQ, UK eas46@cam.ac.uk. 


\section{Abstract}

Primary Objective: To investigate functional improvement late ( $>6$ months) after traumatic brain injury. To this end, we conducted a double-blind, placebo-controlled experimental medicine study to test the hypothesis that a widely used cognitive enhancer would benefit patients with traumatic brain injury (TBI).

Research Design: We focused on motor control function using a sequential finger opposition fMRI paradigm in both patients and age-matched controls.

Methods and Procedures: Patients' fMRI and DTI scans were obtained after randomised administration of methylphenidate or placebo. Controls were scanned without intervention. To assess differences in motor speed, we compared reaction times from the baseline condition of a sustained attention task.

Main Outcomes and Results: Patients' reaction times correlated with wide-spread motor-related white matter abnormalities. Administration of methylphenidate resulted in faster reaction times in patients, which were not significantly different from those achieved by controls. This was also reflected in the fMRI findings in that patients on methylphenidate activated the left inferior frontal gyrus significantly more than when on placebo. Furthermore, stronger functional connections between pre/post-central cortices and cerebellum were noted for patients on methylphenidate.

Conclusions: Our findings suggest that residual functionality in patients with TBI may be enhanced by a single dose of methylphenidate. 


\section{Introduction}

The motor control network (MCN) incorporates remote brain regions and involves shortand long-range interactions between cortical and subcortical areas. Movement involves the integration of information between the motor cortex including the premotor cortex and basal ganglia, cerebellum as well as the peripheral nervous system. Moreover, movement control entails a continuous loop from feedback to feed-forward involving both predictive and reactive processes. Lemon, 2008 [1], provides a comprehensive description of motor control as a process which results from operations involving the entire motor network.

The motor cortex (including the premotor cortex) plans and controls the execution of voluntary motor functions and is considered to be the major source of motor control. Cerebellar-thalamo-cortical interactions are thought to have a role in computing the pattern of muscle activation necessary in order to produce smooth co-ordinated movement [2]. The cerebellum is thought to adapt movement by trial learning mechanisms, although what information is predicted or how the information is derived at the neural circuit level is still debated [3]. The cerebellum also interacts with vestibular and reticular nuclei to provide bilateral postural control [4]. Intact functionality of these systems provides the necessary means for efficient, goal directed movement and conversely impaired activation of these systems results in compromised movement [5].

Following traumatic brain injury ( $\mathrm{TBI})$, alteration in motor control function can result from several mechanisms of injury in the central nervous system (CNS) [6]. These mechanisms may include diffuse axonal injury, deep cerebral haemorrhage, focal 
cortical contusion, transtentorial herniation and hypoxic-ischemic injury [7]. Our group previously examined $\mathrm{MCN}$ reorganisation in patients with $\mathrm{TBI}$ using a finger-thumb opposition paradigm with functional MRI (fMRI) [8]. On that occasion we reported fewer interhemispheric interactions in patients compared to controls as well as the total absence of anticorrelations between $\mathrm{MCN}$ regions, in contrast to healthy controls. Reduced functional connectivity in patients was attributed to compromised interhemispheric structural connectivity, possibly caused by damage to the corpus callosum. Diffusion Tensor Imaging (DTI) data could have confirmed the structural damage hypothesis but unfortunately was not collected on that occasion. Nevertheless, several published reports detail damage to the corpus callosum following TBI [e.g. 9,10,11]. Interhemispheric transfer, thought to be mediated by corpus callosum white matter, is also widely discussed in the ever-expanding ageing literature in relation to maintenance of cognitive function and compensatory cross hemispheric activity $[12,13]$, as well as in the context of motor recovery following stroke $[14,15]$.

Although there is some evidence that motor recovery in patients with TBI stabilises clinically at six months to a year after injury [6], there is increasing evidence to suggest long-term progression of pathology. For example, Ramlackhansingh et al., 2011 [16] reported chronic inflammatory response following TBI and Potts et al., 2009 [17] showed that the injury can evolve up to two years post-insult, highlighting the need to consider TBI as a disease that evolves over time. Yet, later-stage TBI motor control functionality is rarely studied and, to our knowledge, there are no studies using the combination of techniques employed here to elucidate the degree of functionality in relation to structural integrity in patients with TBI. 
To fully understand $\mathrm{TBI}$ progression, it is important to characterise later-stage functionally of brain networks such as the MCN using state-of-the-art technology (e.g. high resolution MRI) combined with appropriate analyses methods. The use of structural and functional connectivity data in addition to activation analyses allows for increased sensitivity in the characterisation of the MCN, since motor tasks involve widespread specialised areas whose modulation is mediated by functional demands [18].

Methylphenidate has proven efficacy in the treatment of attention deficit hyperactivity disorder (ADHD) [19]. Patients with TBI often present with similar symptoms to patients with $A D H D$, and suffer from disrupted attention, compromised concentration and memory problems. Limited evidence also exists of the drug's ability to modulate motor output in TBI [20] and to promote motor recovery in subcortical stroke [21]. Given our previous study demonstrating abnormalities of the $\mathrm{MCN}$ in $\mathrm{TBI}$, and the modulatory effect of methylphenidate on neural activation and motor function in other settings, we undertook a proof of principle study to determine whether a single dose of the drug could improve MCN function following TBI.

The research questions that we attempted to answer using fMRI and DTI data were whether a) patients with TBI have intact structural and functional MCNs and b) whether MCN functional enhancement is possible with a single dose of methylphenidate. We hypothesized, that following methylphenidate administration, activation and functional connectivity patterns in the TBI group would approach those of healthy controls. 


\section{Materials and Methods}

\subsection{Study}

Two experimental groups, healthy controls and patients with later-stage ( $>6$ months after the injury) TBI, participated in an early phase double-blind, placebo-controlled neuroimaging study, which aimed to provide a basis for selecting more targeted neurocognitive enhancers to treat $\mathrm{TBI}$ sequelae. Patients were tested overall for decreased attention span (rapid visual information processing task, [22]), working memory problems (n-back [23]), response inhibition (stop signal [24]), planning (tower of London [25]) and movement control. Our results for the working memory and the response inhibition tasks have been published by Manktelow et al., 2017 [26] and Moreno-Lopez et al., 2017 [27] respectively. This manuscript focuses on the MCN and the impact of methylphenidate on the motor network.

All volunteers underwent MRI imaging (both structural and functional) on a Siemens Trio 3-Tesla-MR system at the Wolfson Brain Imaging Centre, at the University of Cambridge. A computer-generated table was used to randomise initial drug or placebo administration in the patient group. Patients were randomly allocated to be scanned on two separate occasions, 75 minutes after oral administration of either methylphenidate (30 mg) or placebo, in counterbalanced order. $30 \mathrm{mg}$ of methylphenidate was used to ensure an effective dose was given, without increasing the likelihood of side effects. There is evidence of a dose-dependent response to the drug [19] with higher doses found to be more efficacious. Healthy controls were scanned twice without 
pharmacological intervention. The average scan interval for both patients and controls was 2 weeks.

\subsection{Standard protocol approvals, registrations and patient consents}

The Cambridgeshire Research Ethics Committee approved the study, which was conducted according to Good Clinical Practice Guidelines, Declaration of Helsinki and the United Kingdom Central Council Code of Conduct. All volunteers provided informed written consent to participate in the study once experimental procedures had been explained.

\subsection{Participants}

Study participants (both healthy controls and patients) were between 19 and 58 years old and right-handed (handedness was self-reported). Healthy controls were recruited using advertisements around the Addenbrooke's Hospital site in Cambridge. Patients had sustained TBI and been treated on the Neurosciences Critical Care Unit at the hospital. Eighteen patients and 20 healthy controls met the study criteria. However, two of the patients were unable to complete the scanning protocol because they did not tolerate the scanning process. Data from a further two patients were prospectively excluded because of excessive movement during the MRI scan. Six healthy controls were prospectively excluded to achieve evenly age-matched groups. Participants were individually age-matched and mean group differences in age were examined using a two-sample t-test $(\mathrm{HC} 37.43 \pm 12.89$ vs. patients $37.49 \pm 14.07 ; \mathrm{p}=0.99)$. Two experimental groups formed an age-matched sample, composed of 14 healthy controls and 14 patients. The mean duration from injury to first scan was 23 months. 
Patient injury severity was classified using the Glasgow Coma Scale (GCS), as it is still the most commonly used score for classification of $\mathrm{TBI}$ severity in large trauma registries worldwide [28], due to its ease of use and low intra- and inter-rater variability. Our research database records the best available initial GCS. By preference, if the post-resuscitation GCS is available, this is used. However, several patients undergo tracheal intubation at the scene of accident because of airway or cardiorespiratory compromise and cannot have a GCS measured after hospital arrival. In such patients, the initial GCS recorded at the scene of injury was used.

Twelve participants from the TBI sample had a moderate or severe injury, as defined by the GCS at the scene of injury (severe defined as 8 or below and moderate as 9-12). One patient was injured abroad and required intensive care support for five days followed by a further three weeks of hospitalisation. The acute CT scan report showed an intra-cerebral haemorrhage, temporal contusions and skull fractures. Based on this medical history (without an initial GCS score available), the patient was determined to have had a severe injury. Two patients had mild injuries with positive CT findings. Table 1 shows demographics and acute scan results for the TBI participants.

Exclusion criteria for the study included the National Adult Reading Test $<70$, Mini Mental State Exam <23, left-handedness, history of psychiatric or neurological disorders, contraindications for MRI scanning, taking medication that could affect physical or cognitive performance (including tricyclic antidepressants and benzodiazepines), history of drug or alcohol abuse, or women in whom pregnancy had not been excluded (by pregnancy test where required). Further exclusion criteria were marked anxiety, agitation or tension, motor tics or siblings with tics, family history or 
diagnosis of Tourette's syndrome, hyperthyroidism, severe angina, cardiac arrhythmias, severe hypertension, heart failure, glaucoma, thyrotoxicosis, or epilepsy.

In addition, patients were excluded if they had a physical disability that could prevent them from completing the tasks either in the screening or scanning stages, known sensitivity to methylphenidate, if they lived alone, or if they had been recruited into more than three research studies, or any other interventional study within a calendar year.

\section{${ }^{\star \star *}$ Table 1 is at the end of the manuscript ${ }^{\star \star \star}$}

\subsection{Motor speed assessment}

To assess speed of motor response inside the scanner, we used reaction time data from the baseline condition of the Rapid Visual Information Processing (RVIP) task. RVIP measures sustained attention by asking participants to identify sequences of three numbers amongst pseudo-randomly presented single digits [29]. The baseline condition required participants to press their response button when they saw the digit 0 on the screen. This simple reaction time condition was used as an indication of motor speed in the scanning environment for both the healthy controls and the patient group. For the patients, this assessment provided reaction time measurements following the administration of methylphenidate or placebo.

\subsection{The fMRI motor paradigm}

The task utilised a block design involving a 30 second self-paced, repeated sequential finger opposition between thumb and digits 2 to 5 with the right hand during the move 
epochs. Rest epochs lasting for 30 seconds followed movement epochs. Move and rest epochs were repeated five times and were visually cued by words (move or rest) appearing on a screen in the scanner. Participants were briefed on the task before entering the scanner. During the collection of the fMRI data all participants were visually observed to ascertain they were engaging with the task.

\subsection{MRI Imaging}

\subsubsection{Structural and functional MR image acquisition}

After localiser scans, structural T1 scans were acquired to provide anatomical information and to aid spatial normalisation to Montreal Neurological Institute (MNI) space. Acquisition parameters were as follows: repetition time 2300 milliseconds (ms), echo time $2.98 \mathrm{~ms}$, flip angle $9^{0}$, field of view $256 \mathrm{~mm}^{2} \times 256 \mathrm{~mm}^{2}$.

A resting state $\mathrm{fMRI}$ scan was collected after the structural scan and this was followed by the motor task $\mathrm{fMRI}$ data collection. An EPI sequence was utilised to acquire continuous functional images with the following parameters: repetition time $2000 \mathrm{~ms}$, echo time $30 \mathrm{~ms}$, flip angle $78^{0}$, field of view $192 \mathrm{~mm}^{2} \times 192 \mathrm{~mm}^{2}$, 32 slices $3.00 \mathrm{~mm}$ thick with a gap of $0.75 \mathrm{~mm}$ between slices.

DTI data (63 non-collinear directions, $b=1000 \mathrm{~s} / \mathrm{mm}^{2}$ with one volume acquired without diffusion weighting $(b=0)$, echo time $106 \mathrm{~ms}$, repetition time 1700ms, field of view 192 $\mathrm{mm} \times 92 \mathrm{~mm}, 2 \mathrm{~mm}^{3}$ isotropic voxels) were also collected to investigate white matter integrity.

\subsubsection{Preprocessing and analysis of DTI data}


The DTI data were eddy current corrected and realigned using FSL (fsl.fmrib.ox.ac.uk/fsl). Fractional anisotropy (FA) images were calculated and spatially normalised by constructing a study specific template as discussed previously by our group [30]. The spatially normalised images were smoothed with an $8 \mathrm{~mm}$ isotropic Gaussian filter. A voxel-wise fractional anisotropy comparison between healthy controls and patients with TBI was carried out using a two-sample t-test in SPM8. Further, we used reaction time data obtained in the scanner, in a whole brain linear regression analysis to evaluate whether motor speed related to alterations in FA.

Results were considered significant if they reached a p-value of 0.001 uncorrected at the voxel level, and a cluster $p$-value of $\leq 0.05$ FWE corrected for multiple comparisons for a whole brain white matter mask. Significant alterations in fractional anisotropy were $\begin{array}{llll}\text { further } & \text { examined } & \text { with } & \text { MRIcroN }\end{array}$ (http://www.mccauslandcenter.sc.edu/mricro/mricron) utilizing the JHU-white matter atlas to annotate significant clusters.

\subsubsection{Preprocessing and analysis of fMRI data}

Functional MRI data were preprocessed and analysed using SPM8 (www.fil.ion.ucl.ac.uk/spm/) within Matlab (www.mathworks.co.uk/products/matlab).

The first five images of each fMRI scanning session were discarded to allow for MR signal stabilisation. After slice-timing correction and realignment, the T1 structural scan for each volunteer was coregistered with their mean EPI image. The coregistered structural scans were then segmented and the grey matter probabilistic images were spatially normalised to a grey matter template (Montreal Neurological Institute; MNI; 
(http://www.mcgill.ca/neuro/). The normalisation parameters obtained from this process were applied to the realigned $\mathrm{fMRI}$ images, in effect bringing them to $\mathrm{MNI}$ space. Smoothing with an $8 \mathrm{~mm}$ Gaussian kernel was the final preprocessing step. All images were visually inspected after preprocessing to ensure correct spatial normalisation.

Statistical modelling utilised the General Linear Model (GLM) framework. Move and rest onsets (and durations) convolved with the canonical haemodynamic response function were used as regressors of interest at the single subject level.

The healthy control motor control network, as established from the subtractive analysis above, informed whole brain voxel-wise Psychophysiological Interaction (PPI) analyses, carried out to investigate functional connectivity changes with methlyphenidate. The PPI framework allows the extraction of task specific time series and is used to examine how activity in one brain area relates to activity in another brain area in the context of a specific task [31]. The subject level GLM for the PPI models included a task specific time-series for the area of interest as well as 6 movement parameters as confounds. Seeds for the PPI analyses included the left primary motor cortex, the left primary somatosensory cortex, the right cerebellum, the right lateral premotor cortex, the left thalamus, right primary somatosensory cortex and left cerebellum.

Group random-effects analyses for both activation and connectivity analyses were carried out using one-sample, two-sample and paired t-tests to assess group effects and differences. Group level neuroimaging statistics utilised a combination of voxel- and cluster-level thresholds and results were considered significant when they reached a $p$ value of 0.001 uncorrected at the voxel level, and a cluster $p$-value of $\leq 0.05$ corrected 
for multiple comparisons for the entire brain (Family-Wise Error correction, FWE). The peak significant co-ordinates from all neuroimaging analyses were annotated using MRIcroN software (http://www.mccauslandcenter.sc.edu/mricro/mricron) and the automatic anatomical labelling (AAL) atlas [32] as well as Bradmann area templates.

\section{Results}

\subsection{Behavioural data}

Reaction time data confirmed that healthy controls were significantly faster than patients on placebo ( $426.97 \pm 50.6$ vs. $481.57 \pm 68.44 \mathrm{~ms}$, respectively; $p=0.02$, Figure 1$)$. The reaction time comparison between healthy controls and patients on methylphenidate did not produce a significant result $(440.75 \mathrm{~ms} \pm 60.65 ; \mathrm{p}=0.52$, Figure 1$)$. Further, withinpatient group comparison revealed that patient reaction time was significantly faster on methylphenidate than it was on placebo $(p=0.005$, Figure 1$)$. 


\section{RVIP Reaction time in the scanner (ms)}

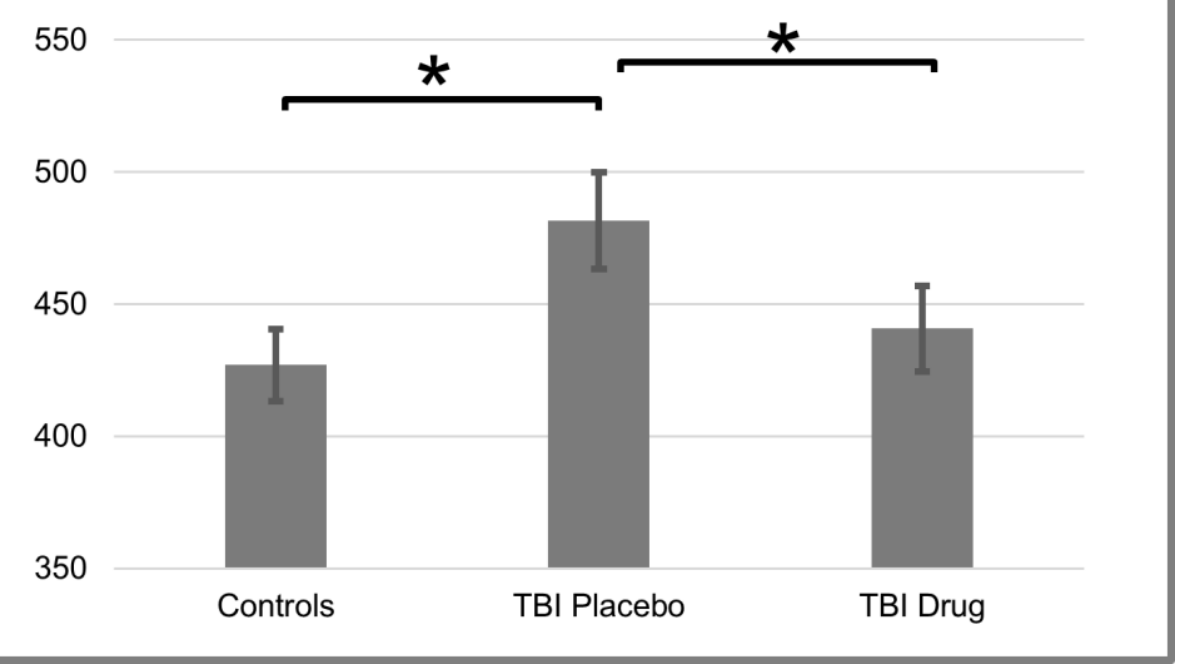

Figure 1: Comparison of reaction times (ms) between healthy controls and patients. Patients were assessed twice on methylphenidate and placebo.

\subsection{Imaging analysis}

\subsubsection{White matter integrity in the patient group}

Near global changes in fractional anisotropy and therefore white matter alteration was seen in the patients when compared to the control group. Patients with TBI had reduced fractional anisotropy in the areas highlighted in Figure 2A. Such widespread changes are expected to have an effect in motor function and in order to test this hypothesis we assessed whether the speed of response after placebo administration was related to reductions in FA. The whole brain multiple linear regression analysis revealed several significant clusters (see Table 2 and Figure 2B for statistical peaks). FA in bilateral 
cerebellar white matter bundles ( $\mathrm{L} \& \mathrm{R}$ middle, superior and inferior cerebellar peduncles) as well as left lateralised white matter bundles ( $L$ external capsule, $L$ anterior limb of internal capsule, $L$ posterior limb of internal capsule, $L$ genu of corpus callosum, $\mathrm{L}$ cingulum, $\mathrm{L}$ posterior corona radiata, $\mathrm{L}$ superior longitudinal fasciculus) and $\mathrm{R}$ posterior thalamic radiation, negatively correlated with reaction times. Lower FA in motor-function-relevant white matter bundles was thus associated with longer reaction times. The cerebellar peduncles, corona radiata/internal capsule, and corpus callosum, have all been implicated in motor function [33].

\section{${ }^{\star \star \star}$ Table 2 is at the end of the manuscript ${ }^{\star \star \star}$}

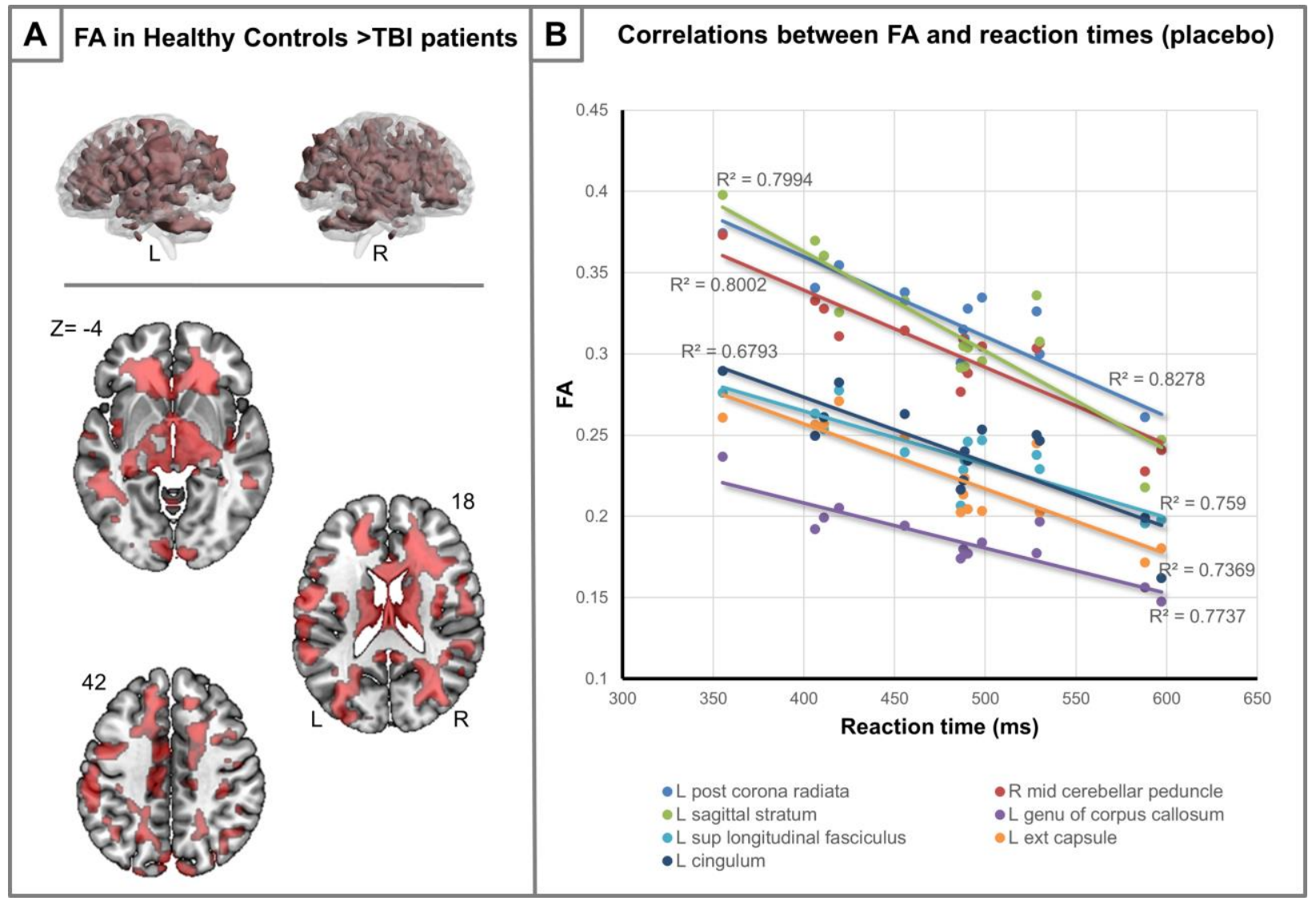


Figure 2: $[\mathrm{A}]$ Widespread FA reductions in patients with $\mathrm{TBI}$ compared to healthy controls. 3D reconstructions demonstrate the widespread extent of changes while orthogonal z slices provide more specific anatomical information. Numbers represent MNI z-axes coordinates. [B] The speed of response for the patients related to reductions in FA in several left lateralised white matter bundles including the left coronal radiate. However, left lateralisation does not persist in the cerebellum where we found bilateral cerebellar peduncles to be related to reaction times.

\subsubsection{Activation results}

During the sequential finger-thumb opposition task, healthy controls activated a network comprising left cerebellum, right lateral premotor region and right supramarginal/somatosensory cortex in addition to areas commonly implicated in motor control function such as left precentral/primary motor cortex (LpreC), left postcentral/primary somatosensory cortex (LpostC) and right cerebellum. After placebo administration, the patients activated a left lateralised (except cerebellum) aspect of the MCN. This comprised a subset of the areas activated in the healthy controls, namely the left primary motor cortex, left primary somatosensory cortex, right cerebellum, left supplementary motor area and left thalamus. Following methylphenidate administration, the patients showed additional activations in the right lateral premotor area, and right supramarginal cortex (Figure 3A, Table 3). 
Patient group comparison (placebo/methylphenidate) revealed a statistically significant cluster in the left inferior frontal gyrus (Figure 3B, Table 4), which activated significantly more when patients were on methylphenidate.

\section{${ }^{\star \star *}$ Table 3 is at the end of the manuscript ${ }^{\star * *}$}

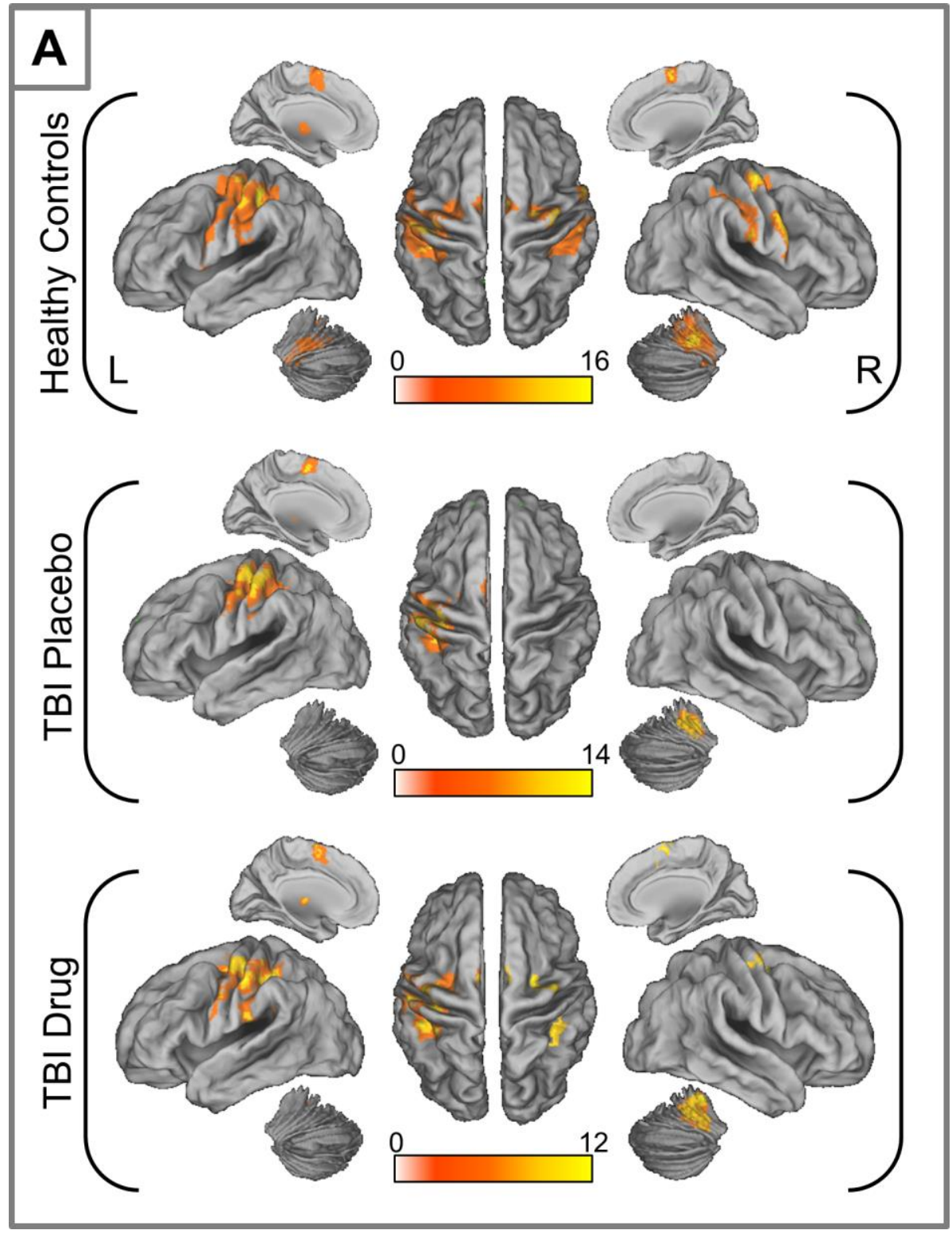




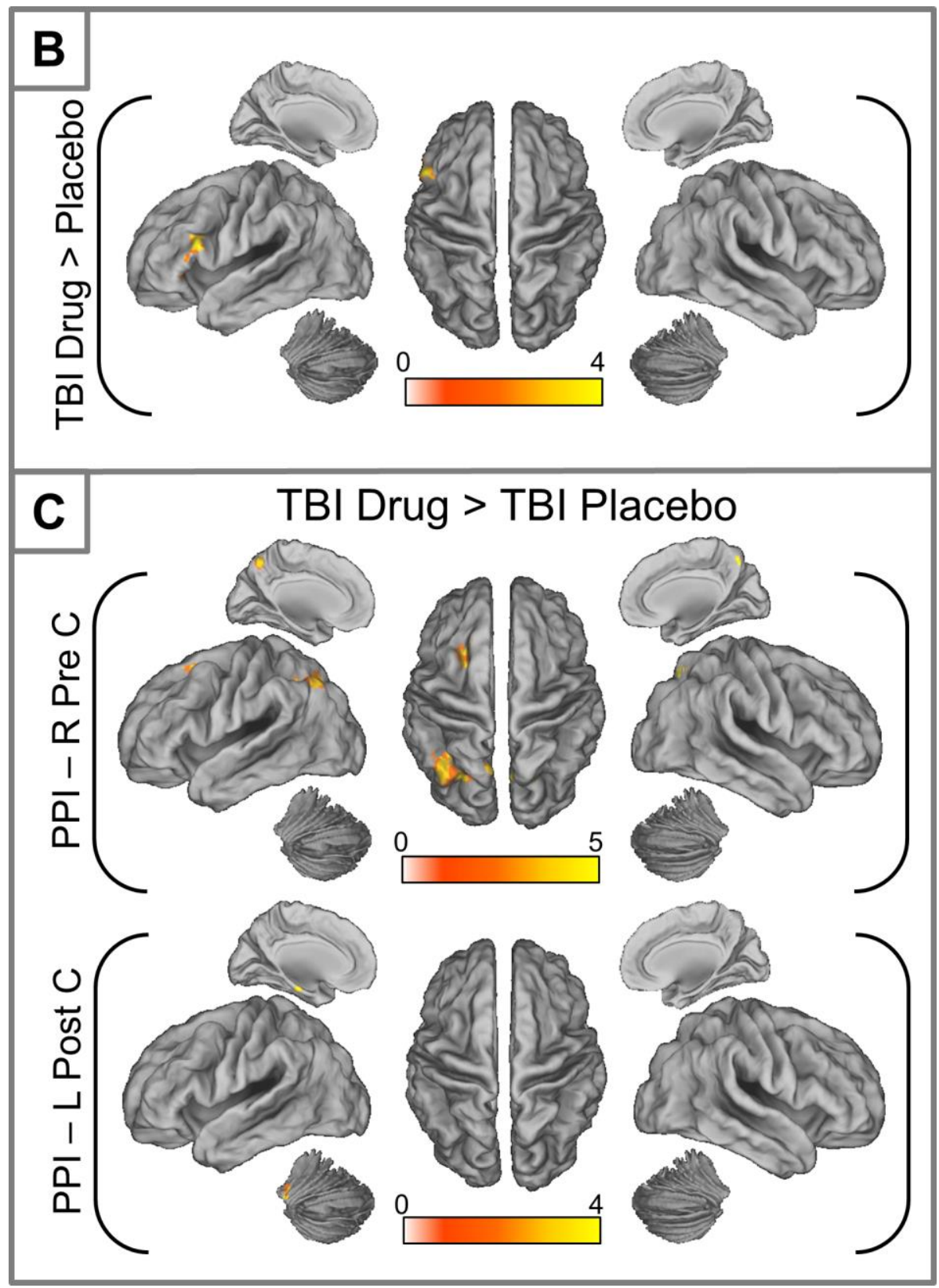

Figure 3: $[\mathrm{A}]$ : $\mathrm{MCN}$ activation in healthy controls and patients with placebo and methylphenidate $[B]$ : Differences in activation between drug and placebo in patients with TBI. [C]: Significant differences in functional connectivity (PPI) in patients with TBI on drug versus placebo from right premotor cortex (top) and left postcentral cortex. Inflated brains were constructed using CARET 
(http://brainvis.wustl.edu/wiki/index.php/Caret:Download)

\section{${ }^{\star \star \star}$ Table 4 is at the end of the manuscript ${ }^{\star \star \star}$}

\subsubsection{Functional connectivity - Whole brain, seed-based connectivity analysis}

Following methylphenidate administration, the patients demonstrated functional connectivity over and above that on placebo, specifically between the right lateral premotor seed and a) the parietal lobe bilaterally and b) the left middle frontal gyrus (Figure 3C). Additionally, when on methylphenidate, the left postcentral cortex significantly increased its functional connectivity with cerebellar areas including the vermis (Figure $3 \mathrm{C}$ ).

In summary, the whole-brain functional connectivity analyses concurred with the structural connectivity data which suggested a compromised MCN following TBI. Over and above this, the functional connectivity data showed stronger MCN connectivity on methylphenidate; a finding that may signify enhanced residual functionality of the MCN network when performing right handed sequential movement. Significantly faster reaction times on methylphenidate also suggest MCN enhancement.

\section{Discussion}

\subsection{Reaction time data in healthy controls versus patients}


The behavioural data we collected and analysed in this study suggested that the healthy control group produced more efficient, faster, motor outputs in keeping with previous findings, which also suggest that, despite apparently good motor recovery, patients with later-stage TBI present with a slowing in motor performance [34]. The reaction time findings in our study were supported by both DTI findings and functional activation/ connectivity results. This slowness in motor function in patients with TBI was ameliorated by methylphenidate. Patients were significantly faster on methylphenidate than on placebo, and not significantly different from healthy controls when they took methylphenidate.

\section{2. $M C N$ activation in patients with later-stage $T B I$}

Healthy controls activated an MCN which included the left primary motor cortex, the left primary somatosensory cortex, the right cerebellum, the right lateral premotor cortex, the left thalamus, right primary somatosensory cortex and left cerebellum. Patients on placebo presented with a subset of the activations we noted in the control group. Methylphenidate administration resulted in an augmented MCN activation, which partly restored the network to control activation levels.

Comparison between patients on methylphenidate and placebo revealed a significant difference in activation in the left inferior frontal cortex. Haggard, 2008 [35] described a frontal cognitive aspect of the motor network, in which the more anterior prefrontal structures are involved in prior action intention. Furthermore, intact interactions between frontal and subcortical areas (basal ganglia and the thalamus) are key when behavioural flexibility and cognitive control over actions is required [7]. Our TBI group 
showed widespread structural disconnections, including those between frontal and subcortical areas as demonstrated by our DTI analysis. These compromised connections may be influencing the reconfiguration and updating of action plans [7]. It is also possible that the additional inferior frontal activation found in this study when patients were on methylphenidate, reflected augmented residual fronto-subcortical interactions, resulting in shorter reaction times.

\subsection{Functional MCN connectivity in patients with later-stage TBI on methylphenidate}

Both our functional and structural connectivity data support the presence of a compromised MCN following TBI. A likely explanation is that white matter structural changes, as evidenced by the DTI data, are causing the changes in functional connectivity we observed during the sequential finger opposition task. Such abnormalities in structural connectivity have been widely reported after TBI $[9,36,37,17,11]$.

Functional connectivity between the right lateral premotor cortex and parietal cortices was augmented by methylphenidate, suggesting enhanced neural processing to support movement output. The lateral premotor cortex plays an important role in the transformation of sensory information into appropriate motor behaviour, with the right lateral premotor area being linked to the performance of motor sequences [38]. It has also been suggested that the lateral premotor areas support other brain regions to integrate information for response and timing of action and possibly to generate the final movement selection for both internal and external actions $[39,40]$. These findings further 
support Frey et al.'s, 2011 [2] proposal that the lateral premotor area is important for action selection, serving as the interface between the prefrontal and parietal association cortices for the primary motor cortex [2].

Furthermore, Zimmerman et al., 2012 [41] found that motor tasks requiring attention switching involve the frontal and parietal lobes, as part of a supramodal frontoparietal attentional network, especially in the right cortical hemisphere, which has been implicated with cortical inhibition in motor tasks. Hence, these structures are overall involved with sensory processing and associative, cognitive processes [38,42,2].

Following methylphenidate administration another cluster which displayed increased connectivity to the right lateral premotor cortex was found in left lateral premotor cortex/left middle frontal gyrus. When task uncertainty is increased, either for response selection or timing, the lateral premotor area has been found to respond bilaterally in healthy controls [39]. Additionally, the left middle frontal gyrus has been linked to attention in motor tasks although this has been more commonly observed in the context of self-initiated rather than cued movements [38]. Overall, the interaction between the sensory processing and associative regions with lateral premotor cortices may signify information transformation/integration from sensory cortices to produce movement $[39,42,38,2,40,43]$.

Increased functional connectivity under methylphenidate was also observed between the left postcentral cortex and the cerebellum. This again highlights the importance of sensory processing to augment motor production as the postcentral cortex is the primary somatosensory cortex with documented links to subcortical structures. 
Increased connectivity of this area to the cerebellum, may influence the timing and correct activation of muscles [2]. The importance of sensory input to driving motor output should not be overlooked and further research in this area may benefit from the use of sensory testing to establish the level of intact sensory information available to patients. Rothwell et al., 1982 [44] suggested that without sensory information movement can become clumsy. Evidence from other studies also highlights the importance of tactile and proprioceptive information for movement production $[45,39,46]$. During movement, sensory information is integrated into motor processing to adjust performance in relation to environmental demands [41]; it remains however unclear how the salience of sensory input is defined within the motor processing pathway [3].

Motor control in patients with later-stage TBI is not widely studied, and to our knowledge, there are no studies using data directly comparable to ours. Our previous study reviewed psychophysiological interactions in the MCN [8], using a simpler fingerto-thumb opposition task. Sequential movements used here, have been found to activate additional areas to those required in less complex movements $[47,48,46,38]$. Data from the current study complements our earlier findings which suggested compromised functional connectivity in the MCN in patients with later-stage TBI, but elucidating causality in these interactions will require additional studies.

\subsection{Methylphenidate and enhancement of the MCN under the drug condition}

Patients on methylphenidate displayed enhanced activations in the left hemisphere and greater functional connectivity. Methylphenidate is thought to increase synaptic 
dopamine [49] and such increases may have resulted in enhanced cortico-striatal loops that modulate motor function [50]. The results in our study suggest that methylphenidate may have augmented motor output in agreement with an earlier study on subcortical stroke [21] where methylphenidate was shown to enhance finger movement. In the subcortical stroke sample, the methylphenidate-induced improvement in motor performance was accompanied by task related cortical activation in the ipsilesional primary sensorimotor cortex and the contralesional, premotor cortex (Tardy et al., 2006). This line of evidence supports the hypothesis that the connectivity patterns we observed with a single dose of methylphenidate could reflect a facilitated, more extensive MCN network which compensates for loss of neural resources within the baseline MCN we observed being recruited on placebo.

Compensatory increases in cortical activation following TBI have been recognised is an important driver of motor recovery [51]. While not addressed by our experiment, enhancement of dopaminergic neurotransmission has also been shown to improve post-training retention of a motor task [50], altogether suggesting that methylphenidate may improve not just motor performance, but also motor learning.

\subsection{Limitations of study}

The main limitation of this study was that the patients we recruited were not screened with extensive motor or sensory assessments. Patients were considered clinically to have 'good' motor outcomes, yet we found alterations in structural and functional connectivity in their MCN. Future studies should assess in detail whether any 
motor/sensory deficits are present. Assessment should also include co-ordination and timing of movements as a way of evaluating subcortical functionality.

Evaluation of tapping rate during scanning would allow for a more reliable assessment of motor output and differences that may exist between healthy controls and patients. Unfortunately MRI compatible hardware to collect tapping rate data was not available during this experiment. Data collected in this manner would provide a precise assessment of potential changes which may be due to alteration in the MCN of patients with later-stage TBI.

Functional MRI studies, even among healthy controls, demonstrate a high level of variability for externally triggered finger movement paradigms $[52,38]$. In future studies, consideration should be given to the manner in which patient variability can be addressed, especially in a patient population recognised as highly heterogeneous [7]. It is possible that variables introduced during data analysis to stratify the subjects into 'higher' or 'lower' movement groups will provide a fairer group evaluation. It is also important that consideration should be given to how patients with later-stage TBI are categorised by injury severity. It is possible that the use of a classification using symptoms, such as loss of consciousness period or length of post-traumatic amnesia, may be more appropriate [0].

Although comparable with previous studies, it would be important to replicate this study with a larger sample size. Specifically, future studies aiming to define the biological mechanisms of methylphenidate on neural networks following TBI should aim to recruit a larger cohort of patients with severe TBI. The heterogeneity of this particular cohort 
makes it difficult to generalize findings but with a larger number of patients the statistical power would be improved resulting in more generalizable identification of the differences in motor outcomes within TBI groups.

Finally, our study did not include patients with major motor control problems. The main reason for this is that other fMRI tasks utilised in this study (working memory, planning, sustained attention, response inhibition) required button pressing. The use of resting state fMRI in future studies will allow the assessment of the motor control network in patients with severe TBI without requiring a response in the scanner environment.

\subsection{Conclusions}

The MCN was not characterised extensively by this early phase study; however, this study revealed specific structural and functional connectivity changes in patients with later-stage TBI. MCN augmentation following the administration of methylphenidate in patients with TBI resulted in restoration of reaction times making them similar to those observed in healthy controls. The immediate effects of the drug suggest that the methylphenidate-induced modulation of the MCN that we observed could have application in physical rehabilitation in later-stage motor deficits following $\mathrm{TBI}$ by supporting residual connectivity. 


\section{Declaration of Interest}

The study was funded by the Evelyn Trust- grant number 06/20. C.D. was funded by the Clinical Academic Research Awards organized by the East of England Multi Professional Deanery. B.J.S. consults for Cambridge Cognition, Otsuka, Servier and Lundbeck. She holds a grant from Janssen/J\&J and has share options in Cambridge Cognition. D.K.M. is supported by the Neuroscience Theme of the NIHR Cambridge Biomedical Research Centre and NIHR Senior Investigator awards, and by Framework Program 7 funding from the European Commission (TBIcare). He has received lecture and consultancy fees and support for research from Glaxo SmithKline, Solvay and Linde. E.A.S. is funded by the Stephen Erskine Fellowship, Queens' College, Cambridge, UK. 


\section{References}

1. Lemon RN. Descending pathways in motor control. Annual Review of Neuroscience. 2008;31,195-218.

2. Frey SH, Fogassi L, Grafton S, Picard N, Rothwell JC, Schweighofer N, Corbetta M, Fitzpatrick, S.M. Neurological principles and rehabilitation of action disorders: computation, anatomy and physiology. CAP) model. Neurorehabil Neural Repair 2011;25. 5 Suppl. 6S-20S.

3. Bastian AJ. Learning to predict the future: the cerebellum adapts feedforward movement control. Curr Opin Neurobiol. 2006;16: 645-649.

4. Kuypers HGJM. Anatomy of the descending pathways. In Brookhart JM, Mountcastle VB, Brooks VB and Geiger SR (Eds). Handbook of Physiology. Baltimore: Williams and Wilkins. 1981.

5. Meadows $L$ and Williams $J$. An Understanding of Functional Movement as a Basis for Clinical Reasoning. In Raine S, Meadows L, Lynch-Ellerington M (Eds). Bobath Concept. Theory and Clinical practice in Neurological Rehabilitation. Chichester: Wiley-Blackwell. 2009.

6. Jang, SH. Review of motor recovery in patients with traumatic brain injury. NeuroRehabilitation. 2009;24: 349-353.

7. Leunissen I, Coxon JP, Caeyenberghs K, Michiels K, Sunaert S, Swinnen SP. Subcortical volume analysis in traumatic brain injury: The importance of the fronto-striato-thalamic circuit in task switching. Cortex 2014;51:67-81. 
8. Kasahara M, Menon DK, Salmond CH, Outtrim JG, Taylor Tavares JV, Carpenter TA, Pickard JD, Sahakian BJ, Stamatakis E A. Altered functional connectivity in the motor network after traumatic brain injury. Neurology 2010;75:168-176.

9. Caeyenberghs K, Leemans A, Coxon J,Leunissen I, DriiKoningen D, Geurts M, Gooijers J, Michiels K, Sunaert S, Swinnen SP. Bimanual coordination and corpus callosum microstructure in young adults with traumatic brain injury: a diffusion tensor imaging study. J Neurotrauma 2011;28:897-913.

10. Chang MC, Jang SH. Corpus callosum injury in patients with diffuse axonal injury: a diffusion tensor imaging study. NeuroRehabilitation 2010;26:339-45.

11. Newcombe V, Chatfield D, Outtrim J, Vowler S, Manktelow A, Cross J, Scoffings D, Coleman M, Huchinson P, Coles J, Carpenter TA, Pickard J, Williams G, Menon D. Mapping traumatic axonal injury using diffusion tensor imaging: correlations with functional outcome. PLoS One 2011;6:e19214.

12. Berlingeri M, Danelli L, Bottini G, Sberna M, Paulesu E. Reassessing the HAROLD model: is the hemispheric asymmetry reduction in older adults a special case of compensatory-related utilisation of neural circuits? Exp Brain Res 2013;224:393-410.

13. Cabeza R. Hemispheric asymmetry reduction in older adults: the HAROLD model. Psychol Aging 2002;17:85-100.

14. Calautti C, Naccarato M, Jones PS, Sharma N, Day DD, Carpenter AT, Bullmore ET, Warburton EA, Baron JC. The relationship between motor deficit and hemisphere activation balance after stroke: A $3 T$ fMRI study. Neuroimage 2007;34:322-31. 
15. Calautti C, Jones PS, Naccarato M, Sharma N, Day DJ, Bullmore ET, Warburton EA, Baron JC. The relationship between motor deficit and primary motor cortex hemispheric activation balance after stroke: longitudinal fMRI study. J Neurol Neurosurg Psychiatry 2010;81:788-92.

16. Ramlackhansingh AF, Brooks DJ, Greenwood RJ, Bose SK, Turkheimer FE, Kinnunen KM, Gentleman S, Heckemann RA, Gunanayagam K, Gelosa G, Sharp D J. Inflammation after trauma: microglial activation and traumatic brain injury. Ann Neurol 2011;70:374-83.

17. Potts MB, Adwanikar H, Noble-Haeusslein LJ. Models of traumatic cerebellar injury. Cerebellum 2009;8:211-21.

18. Friston KJ. Functional and effective connectivity: a review. Brain Connect 2011;1:13-36.

19. Faraone SV, Spencer T, Aleardi M, Pagano C, Biederman J. Meta-analysis of the efficacy of methylphenidate for treating adult attention-deficit/hyperactivity disorder. J Clin Psychopharmacol 2004;24:24-9.

20. Plenger PM, Dixon CE, Castillo RM, Frankowski RF, Yablon SA, Levin HS. Subacute methylphenidate treatment for moderate to moderately severe traumatic brain injury: a preliminary double-blind placebo-controlled. Arch Phys Med Rehabil 1996;77:536-40.

21. Tardy J, Pariente J, Leger A, Dechaumont-Palacin S, Gerdelat, A, Guiraud V, Conchou F, Albucher JF, Marque P, Franceries X, Cognard C, Rascol O, Chollet F, Loubinoux I. Methylphenidate modulates cerebral post-stroke reorganization. Neuroimage 2006;33:913-22. 
22. Coull JT, Frith CD, Frackowiak RSJ and Grasby PM. fronto-parietal network for rapid visual information processing: a PET study of sustained attention and working memory. Neuropsychologia. 1996;34:1085- 1095.

23. Sanchez-Carrion R, Fernandez-Espejo D, Junque C, Falcon C, Bargallo N, Roig T, Bernabeu M, Tormos JM, Vendrell P. A longitudinal fMRI study of working memory in severe TBI patients with diffuse axonal injury. Neuroimage. 2008;43:421-9.

24. Chamberlain SR, Hampshire A, Müller U, Rubia K, Del Campo N, Craig K, Regenthal R, Suckling J, Roiser JP, Grant JE, Bullmore ET, Robbins TW, Sahakian BJ. Atomoxetine modulates right inferior frontal activation during inhibitory control: a pharmacological functional magnetic resonance imaging study. Biol Psychiatry. 2008;65:550-5.

25. Cazalis F, Feydy A, Valabrègue R, Pélégrini-Issac M, Pierot L, Azouvi P. fMRI study of problem-solving after severe traumatic brain injury. 2006;20:1019-28.

26. Manktelow AE, Menon DK, Sahakian BJ, Stamatakis EA. Working Memory after Traumatic Brain Injury: The Neural Basis of Improved Performance with Methylphenidate. Front Behav Neurosci. 2017;11:58.

27. Moreno-López L, Manktelow AE, Sahakian BJ, Menon DK, Stamatakis EA. Anything goes? Regulation of the neural processes underlying response inhibition in TBI patients. Eur Neuropsychopharmacol. 2017;27:159-169.

28. Grote S, Bocker W, Mutschler W, Bouillon B, Lefering R. Diagnostic value of the Glasgow Coma Scale for traumatic brain injury in 18,002 patients with severe multiple injuries. J Neurotrauma 2011;28:527-34. 
29. Sahakian B, Jones G, Levy R, Gray J, Warburton D. The effects of nicotine on attention, information processing, and short-term memory in patients with dementia of the Alzheimer type. Br J Psychiatry 1989;154:797-800.

30. Stamatakis EA, Shafto MA, Williams G, Tam P, Tyler LK. White matter changes and word finding failures with increasing age. PLoS One 2011;6:e14496.

31. Friston KJ, Buchel C, Fink GR, Morris J, Rolls E, Dolan RJ. Psychophysiological and modulatory interactions in Neuroimaging. Neuroimage 1997;6:218-229.

32. Tzourio-Mazoyer N, Landeau B, Papathanassiou D, Crivello F, Etard O, Delcroix N, Mazoyer B, Joliot M. Automated anatomical labeling of activations in SPM using a macroscopic anatomical parcellation of the MNI MRI single-subject brain. Neuroimage 2002;15:273-89.

33. Catani M, Thiebaut de Schotten M. A diffusion tensor imaging tractography atlas for virtual in vivo dissections. Cortex 2008;44:1105-32.

34. Incoccia C, Formisano R, Muscato P, Reali G, Zoccolotti P. Reaction and movement times in individuals with chronic traumatic brain injury with good motor recovery. Cortex. 2004;40:111-5.

35. Haggard P. Human volition: towards a neuroscience of will. Nat. Rev. Neurosci. 2008;9:934-46.

36. Choi GS, Kim OL, Kim SH, Ahn SH, Son SM, Jang SH. Classification of cause of motor weakness in traumatic brain injury using diffusion tensor imaging. Arch Neurol 2012;69:363-67. 
37. Kim DG, Kim SH, Kim OL, Cho YW, Son SM, Jang SH. Long-term recovery of motor function in a quadriplegic patient with diffuse axonal injury and traumatic hemorrhage: a case report. NeuroRehabilitation 2009;25:117-22.

38. Witt ST, Laird AR, Meyerand ME. Functional neuroimaging correlates of fingertapping task variations: an ALE meta-analysis. Neuroimage 2008;42:343-56.

39. Sakai K, Hikosaka O, Takino R, Miyauchi S, Nielsen M, Tamada T. What and when: parallel and convergent processing in motor control. J Neurosci 2000;20:2691-700.

40. Hoffstaedter F, Grefkes C, Zilles K, Eickhoff SB. The "what" and "when" of selfinitiated movements. Cereb Cortex 2013;23:520-30.

41.Zimmermann KM, Bischoff M, Lorey B, Stark R, Munzert J, Zentgraf K. Neural Correlates of Switching Attentional Focus during Finger Movements: An fMRI Study. Front Psychol. 2012;3:555.

42. Vaillancourt DE, Mayka MA, Corcos, DM. Intermittent visuomotor processing in the human cerebellum, parietal cortex, and premotor cortex. J Neurpphysiol 2006;95:922-31.

43. Seghier, ML. The angular gyrus: multiple functions and multiple subdivisions. Neuroscientist. 2013;19:43-61.

44. Rothwell JC, Traub MM, Day BL, Obeso JA, Thomas PK, Marsden CD. Manual motor performance in a deafferented man. Brain 1982;105:515-42.

45. Rausch M, Spengler F, Eysel UT. Proprioception acts as the main source of input in human S-I activation experiments: a functional MRI study. Neuroreport 1998;9:2865-68. 
46. Solodkin A, Hlustik P, Noll DC, Small SL. Lateralization of motor circuits and handedness during finger movements. Eur J Neurol 2001;8:425-34.

47. Cui SZ, Li EZ, Zang YF, Weng XC, Ivry R, Wang JJ. Both sides of human cerebellum involved in preparation and execution of sequential movements. Neuroreport. 2000;11:3849-53.

48. Haaland KY, Elsinger CL, Mayer AR, Durgerian S, Rao SM. Motor sequence complexity and performing hand produce differential patterns of hemispheric lateralization. J Cogn Neurosci. 2004;16:621-36.

49. Volkow ND, Wang GJ, Fowler JS, Telang F, Maynard L, Logan J, Gatley SJ, Pappas N, Wong C, Vaska P, Zhu W, Swanson JM. Evidence that methylphenidate enhances the saliency of a mathematical task by increasing dopamine in the human brain. Am J Psychiatry 2004;161:1178-80.

50. Abe M, Schambra H, Wassermann EM, Luckenbaugh D, Schweighofer N, Cohen LG. Reward Improves Long-Term Retention of a Motor Memory through Induction of Offline Memory Gains. Curr Biol 2011;21:557-562.

51. Villamar MF, Santos Portilla A, Fregni F, Zafonte R. Noninvasive brain stimulation to modulate neuroplasticity in traumatic brain injury. Neuromodulation 2012;15:326-38.

52. Wiese H, Tonnes C, de Greiff A, Nebel K, Diener H-C, Stude P. Self-initiated movements in chronic prefrontal traumatic brain injury: An event-related MRI study. Neuroimage 2006;30:1292-301.

Numminen HJ. The incidence of traumatic brain injury in an adult population--how to classify mild cases? Eur J Neurol 2011;18:460-4. 


\section{Tables}

Table 1: Demographic data and acute CT scan results for TBI patients. SAH Subarachnoid haemorrhage; DAI Diffuse Axonal Injury; EDH Extradural haemorrhage; SDH Subdural hematoma.

\begin{tabular}{|c|c|c|c|c|}
\hline $\begin{array}{l}\text { Time } \\
\text { injury to } \\
\text { scan } 1 \\
\text { (months) }\end{array}$ & $\begin{array}{l}\text { Age at } \\
\text { scan }\end{array}$ & Sex & $\begin{array}{ll}\text { GSC } & \text { on } \\
\text { scene } & \end{array}$ & Scan results (acute) \\
\hline 25 & $\begin{array}{l}27 \\
\text { years } 5 \\
\text { months }\end{array}$ & $\bar{M}$ & 7 & $\begin{array}{l}\text { Blood products surface both frontal } \\
\text { lobes at grey/white matter interfaces } \\
\text { and corpus callosm. No mass lesion }\end{array}$ \\
\hline 18 & $\begin{array}{l}55 \\
\text { years } 7 \\
\text { months }\end{array}$ & $\mathrm{F}$ & 12 & L SAH sulci, frontoparietal convexity \\
\hline 14 & $\begin{array}{l}29 \\
\text { years } 1 \\
\text { month }\end{array}$ & M & 5 & $\begin{array}{l}\text { Multiple haemorrhagic contusions } L \\
\text { temporal lobe. Haemorrhage } L \text { basal } \\
\text { ganglia. } R \text { thalamus. } R \text { subcortical } \\
\text { diffuse axonal injury }\end{array}$ \\
\hline 37 & $\begin{array}{l}49 \\
\text { years } 9 \\
\text { months }\end{array}$ & $\mathrm{F}$ & 5 & $\begin{array}{l}\text { Small foci } L \text { cerebral peduncle and } \\
\text { superior frontal lobes }\end{array}$ \\
\hline 32 & $\begin{array}{l}19 \\
\text { years } 3 \\
\text { months }\end{array}$ & M & 7 & No abnormality. Subarachnoid blood \\
\hline 10 & $\begin{array}{l}58 \\
\text { years } 9 \\
\text { months }\end{array}$ & M & 14 & $\begin{array}{l}\text { Haemorrhages orbital frontal cortex. } \\
\text { Subarachnoid_blood }\end{array}$ \\
\hline 40 & $\begin{array}{l}21 \\
\text { years } 6 \\
\text { months }\end{array}$ & M & 5 & $\begin{array}{l}\text { Multiple petechial haemorrhages, } \\
\text { basal cisterns obliterated, SAH, DAI. } \\
\text { Small midline shift to } L\end{array}$ \\
\hline 8 & $\begin{array}{l}19 \\
\text { years } 4\end{array}$ & M & 8 & $\mathrm{R}$ frontoparietal extra-dural. Subdural \\
\hline
\end{tabular}




\begin{tabular}{|c|c|c|c|c|}
\hline & months & & & haematoma. $\mathrm{R}$ parietal fracture \\
\hline 27 & $\begin{array}{l}49 \\
\text { years } 8 \\
\text { months }\end{array}$ & $\mathrm{M}$ & 8 & $\begin{array}{l}\text { Haemorrhagic contusion } \mathrm{L} \text { lentiform } \\
\text { nucleus. Small focal lesion pons. } \\
\text { Bilateral subcortical area frontal lobes. } \\
\text { Signal change in corpus callosm }\end{array}$ \\
\hline 11 & $\begin{array}{l}36 \\
\text { years } \\
11 \\
\text { months }\end{array}$ & $\mathrm{M}$ & 6 & $\begin{array}{l}\mathrm{R} \text { temporal EDH, haemorrhagic } \\
\text { contusions anterior aspect } \mathrm{L} \text { temporal } \\
\text { lobe, posterior inferior } \mathrm{R} \text { frontal lobe. } \\
\text { Scattered areas traumatic SAH in } \\
\text { interpeduncular fossa and some of the } \\
\text { posterior convexity sulci of both } \\
\text { hemispheres }\end{array}$ \\
\hline 26 & $\begin{array}{l}26 \\
\text { years } \\
10 \\
\text { months }\end{array}$ & $\mathrm{M}$ & 7 & Intraventricular haemorrhage \\
\hline 41 & $\begin{array}{l}34 \\
\text { years } 5 \\
\text { months }\end{array}$ & $\mathrm{F}$ & Unavailable & $\begin{array}{l}\text { Intra-cerebral haemorrhage. } \mathrm{R} \\
\text { temporal contusion }\end{array}$ \\
\hline 6 & $\begin{array}{l}43 \\
\text { years } 2 \\
\text { months }\end{array}$ & $M$ & 10 & $\mathrm{R} \mathrm{SAH}$ and SDH \\
\hline 33 & $\begin{array}{l}53 \\
\text { years } 2 \\
\text { months }\end{array}$ & $\mathrm{M}$ & 14 & $\begin{array}{l}\mathrm{R} \text { SAH and SDH. Haemorrhagic } \\
\text { contusion } \mathrm{R} \text { posterior temporal lobes. } \\
\text { Multiple areas contusion superior } \\
\text { frontal lobes and } \mathrm{R} \text { cerebellar } \\
\text { hemisphere, } \mathrm{R} \text { temporal and inferior } \\
\text { frontal lobes }\end{array}$ \\
\hline
\end{tabular}


Table 2: Significant peak voxels from the linear regression evaluating the relationship between FA and reaction times following placebo administration.

\begin{tabular}{|l|l|l|l|l|l|l|}
\hline $\begin{array}{l}\text { p- } \\
\text { value }\end{array}$ & Extent & $\mathrm{X}$ & $\mathrm{y}$ & $\mathrm{z}$ & $\mathrm{t}$-score & Peak in cluster \\
\hline 0.006 & 2455 & -18 & -41 & 44 & 7.6 & L posterior corona radiata \\
\hline 0.000 & 6229 & 8 & -58 & -30 & 6.93 & R Middle cerebellar peduncle \\
\hline 0.010 & 2175 & -48 & -26 & -20 & 6.6 & $\begin{array}{l}\text { L Sagittal stratum (include inferior } \\
\text { longitudinal fasciculus and inferior } \\
\text { fronto-occipital fasciculus) }\end{array}$ \\
\hline 0.015 & 2002 & -6 & 16 & -7 & 6.41 & L Genu of corpus callosum \\
\hline 0.006 & 2466 & -47 & -32 & 36 & 6.14 & L superior Longitudinal Fasciculus \\
\hline 0.023 & 1798 & -29 & 3 & 6 & 5.8 & L external Capsule \\
\hline 0.015 & 2009 & -3 & 18 & 27 & 5.04 & L Cingulum \\
\hline
\end{tabular}


Table 3: Significant peak voxel activations in the MCN in all experimental groups are reported for clusters surviving a voxel threshold of $p \leq 0.001$ uncorrected and cluster threshold of $p \leq 0.05$ FWE-corrected for multiple comparisons.

\begin{tabular}{|c|c|c|c|c|c|c|c|c|}
\hline $\begin{array}{l}\text { Subject } \\
\text { group }\end{array}$ & $p$-value & Extent & $X$ & $y$ & $z$ & t-score & BA & Peak in cluster \\
\hline \multirow[t]{8}{*}{ Controls } & 0.000 & 5311 & $\begin{array}{l}-40 \\
-36 \\
-48\end{array}$ & $\begin{array}{l}-30 \\
-24 \\
-22\end{array}$ & $\begin{array}{l}50 \\
64 \\
48\end{array}$ & $\begin{array}{l}17.76 \\
13.18 \\
11.79\end{array}$ & $\begin{array}{l}3 \\
4 \\
3\end{array}$ & $\begin{array}{l}\text { L postcentral } \\
\text { L precentral } \\
\text { L postcentral }\end{array}$ \\
\hline & 0.000 & 1845 & $\begin{array}{l}22 \\
14 \\
6 \\
\end{array}$ & $\begin{array}{l}-52 \\
-50 \\
-62 \\
\end{array}$ & $\begin{array}{l}-24 \\
-20 \\
-18 \\
\end{array}$ & $\begin{array}{l}16.00 \\
15.24 \\
8.55 \\
\end{array}$ & & $\begin{array}{l}R \text { cerebellum } \\
R \text { cerebellum } \\
\text { Vermis }\end{array}$ \\
\hline & 0.000 & 411 & $\begin{array}{l}58 \\
58\end{array}$ & $\begin{array}{l}10 \\
4\end{array}$ & $\begin{array}{l}18 \\
38\end{array}$ & $\begin{array}{l}13.08 \\
10.40\end{array}$ & $\begin{array}{l}6 \\
6\end{array}$ & $\begin{array}{l}\mathrm{R} \text { precentral } \\
\mathrm{R} \text { precentral }\end{array}$ \\
\hline & 0.000 & 699 & $\begin{array}{l}40 \\
28\end{array}$ & $\begin{array}{l}-12 \\
-12 \\
\end{array}$ & $\begin{array}{l}62 \\
56\end{array}$ & $\begin{array}{l}10.76 \\
8.66\end{array}$ & $\begin{array}{l}6 \\
6 \\
\end{array}$ & $\begin{array}{l}\mathrm{R} \text { precentral } \\
\mathrm{R} \text { precentral }\end{array}$ \\
\hline & 0.000 & 741 & $\begin{array}{l}-22 \\
-18 \\
\end{array}$ & $\begin{array}{l}-54 \\
-68 \\
\end{array}$ & $\begin{array}{l}-26 \\
-22 \\
\end{array}$ & $\begin{array}{l}9.19 \\
6.48 \\
\end{array}$ & & $\begin{array}{l}\mathrm{L} \text { cerebellum } \\
\mathrm{L} \text { cerebellum }\end{array}$ \\
\hline & 0.000 & 1063 & -14 & -20 & 2 & 9.03 & & $\mathrm{~L}$ thalamus \\
\hline & 0.000 & 1051 & $\begin{array}{l}46 \\
64 \\
60\end{array}$ & $\begin{array}{l}-30 \\
-14 \\
-18\end{array}$ & $\begin{array}{l}42 \\
26 \\
20\end{array}$ & $\begin{array}{l}8.44 \\
7.83 \\
7.77 \\
\end{array}$ & $\begin{array}{l}2 \\
43 \\
48 \\
\end{array}$ & $\begin{array}{l}R \text { supramarginal } \\
R \text { supramarginal } \\
R \text { supramarginal }\end{array}$ \\
\hline & 0.013 & 205 & $\begin{array}{l}12 \\
26 \\
6\end{array}$ & $\begin{array}{l}-66 \\
-54 \\
-68\end{array}$ & $\begin{array}{l}-46 \\
-42 \\
-36\end{array}$ & $\begin{array}{l}8.23 \\
4.74 \\
4.59 \\
\end{array}$ & & $\begin{array}{l}R \text { cerebellum } \\
R \text { cerebellum } \\
\text { Vermis }\end{array}$ \\
\hline \multirow[t]{4}{*}{ Placebo } & 0.000 & 2444 & $\begin{array}{l}-38 \\
-38 \\
-46 \\
\end{array}$ & $\begin{array}{l}-24 \\
-20 \\
-26 \\
\end{array}$ & $\begin{array}{l}52 \\
62 \\
54 \\
\end{array}$ & $\begin{array}{l}13.16 \\
10.91 \\
10.54 \\
\end{array}$ & $\begin{array}{l}3 \\
4 \\
3 \\
\end{array}$ & $\begin{array}{l}\text { L postcentral } \\
\text { L precentral } \\
\text { L postcentral }\end{array}$ \\
\hline & 0.000 & 381 & $\begin{array}{l}-6 \\
-10\end{array}$ & $\begin{array}{l}-4 \\
4\end{array}$ & $\begin{array}{l}56 \\
60\end{array}$ & $\begin{array}{l}11.26 \\
5.14\end{array}$ & $\begin{array}{l}6 \\
6\end{array}$ & $\begin{array}{l}\text { L SMA } \\
\text { L SMA }\end{array}$ \\
\hline & 0.000 & 537 & 14 & -52 & -28 & 10.28 & & $\mathrm{R}$ cerebellum \\
\hline & 0.000 & 297 & $\begin{array}{l}-16 \\
-24 \\
-30\end{array}$ & $\begin{array}{l}-18 \\
-12 \\
-18 \\
\end{array}$ & $\begin{array}{l}6 \\
2 \\
0\end{array}$ & $\begin{array}{l}7.71 \\
6.49 \\
5.38\end{array}$ & & $\begin{array}{l}\text { L thalamus } \\
\mathrm{L} \text { pallidum } \\
\text { L putamen }\end{array}$ \\
\hline \multirow[t]{3}{*}{ Drug } & 0.000 & 2919 & $\begin{array}{l}-34 \\
-36 \\
-44 \\
\end{array}$ & $\begin{array}{l}-8 \\
-20 \\
-36 \\
\end{array}$ & $\begin{array}{l}54 \\
54 \\
46 \\
\end{array}$ & $\begin{array}{l}11.81 \\
11.47 \\
9.93 \\
\end{array}$ & $\begin{array}{l}6 \\
4 \\
2 \\
\end{array}$ & $\begin{array}{l}\text { L precentral } \\
\text { L precentral } \\
\text { L inferior parietal }\end{array}$ \\
\hline & 0.000 & 421 & $\begin{array}{l}-14 \\
-28 \\
-20\end{array}$ & $\begin{array}{l}-14 \\
-22 \\
-6\end{array}$ & $\begin{array}{l}8 \\
4 \\
4\end{array}$ & $\begin{array}{l}11.06 \\
6.83 \\
6.61\end{array}$ & & $\begin{array}{l}\mathrm{L} \text { thalamus } \\
\mathrm{L} \text { putamen } \\
\mathrm{L} \text { pallidum }\end{array}$ \\
\hline & 0.000 & 580 & -6 & -4 & 68 & 9.11 & 6 & L SMA \\
\hline
\end{tabular}




\begin{tabular}{|l|l|l|l|l|l|l|l|l|}
\hline & & & -2 & 0 & 58 & 7.49 & 6 & L SMA \\
\hline & 0.000 & 747 & 6 & -48 & -10 & 9.94 & & Vermis \\
& & & 20 & -56 & -18 & 6.77 & & R cerebellum \\
& & & 14 & -60 & -14 & 6.33 & & R cerebellum \\
\hline & 0.000 & 309 & 26 & -6 & 66 & 8.51 & 6 & R superior frontal \\
& & & 40 & -6 & 62 & 6.30 & 6 & R prefrontal \\
\hline & 0.003 & 191 & 38 & -34 & 40 & 6.18 & 40 & R supramarginal \\
& & & 40 & -40 & 46 & 4.89 & 40 & R inferior parietal \\
\hline
\end{tabular}


Table 4: Significant peak voxel activations for the difference between patients on methylphenidate and patients on placebo.

\begin{tabular}{|l|l|l|l|l|l|l|l|l|}
\hline Contrast & $\begin{array}{l}\mathrm{p}- \\
\text { value }\end{array}$ & Extent & $\mathrm{X}$ & $\mathrm{y}$ & $\mathrm{z}$ & $\begin{array}{l}\mathrm{t}- \\
\text { score }\end{array}$ & $\mathrm{BA}$ & Peak in cluster \\
\hline Drug- & 0.000 & 311 & -54 & 20 & 20 & 4.43 & 48 & L Inferior triangularis \\
Placebo & & & -54 & 28 & 10 & 3.29 & 45 & L Inferior triangularis \\
& & & -50 & 24 & -6 & 3.27 & 38 & L Inferior orbitalis \\
\hline
\end{tabular}

